УДК 339.924

Наталия КОНДРАТЬЕВА

\title{
МОДЕЛЬ ИНТЕГРАЦИИ РЫНКОВ ЕС: ЧЕТВЕРТЬ ВЕКА СПУСТЯ ${ }^{1}$
}

\begin{abstract}
Аннотация. В статье дано системное представление об устройстве единого внутреннего рынка ЕС, его логике и методах регулирования, задуманных в 1950-1980 гг. и апробированных 25-летней практикой. С опорой на операционалистский подход произведён поиск содержания понятия “единый внутренний рынок”. Цель статьи - представить единый внутренний рынок как функционирующую модель, имеющую принципиальную основу и взаимосвязанные механизмы. Предложенные определения и видение европейской модели интеграции рынков могут служить методологической базой для дальнейшего описания феномена, анализа индикаторов его развития и решения концептуальных вопросов евразийской экономической интеграции.
\end{abstract}

Ключевые слова: ЕС, единый внутренний рынок, теории интеграции, европейская экономическая модель.

В 2018 г. Европейский Союз отмечает 25-летие создания единого внутреннего рынка (ЕВР). Единство рынков государств-членов признано главным достижением и активом EC [Juncker, 2014: 7]. Результативность ЕВР, измеряемая большим числом индикаторов, - предмет пристального внимания со сторонь наднациональных институтов ${ }^{2}$.

В российской европеистике общий/единый рынок подробно изучают с момента его зарождения [Борко и др., 1963; Шишков, 1979; Борко, 2003: 84-113; Иванов, 2004: 19-34, Гутник, Хесин, 2006; Кондратьева, 2017, Механизм единого рынка, 1992: 50-70]. С начала 2000-х гг. исследования приобрели практическое значение

${ }^{1}$ Статья выполнена при поддержке РФФИ: проект № 17-07-00053-ОГН “Достижения и перспективы интеграции рынков: ЕС, ЕАЭС, ТТИП, интеграция интеграций”.

${ }^{2}$ См.: Report on single market integration and competitiveness in the EU and its member states, 2015; Study on the Impact of the Single Market on Cohesion: Implications for Cohesion Policy, Growth and Competitiveness, 2011.

(C) Кондратьева Наталия Борисовна - кандидат экономических наук, доцент, ученый секретарь Института Европы РАН. Адрес: 125009, Россия, Москва, ул. Моховая, д. 11-3; доцент НИУ “Высшая школа экономики”. Адрес: 101000, Россия, Москва, Мясницкая ул., 20, зав. кафедрой европейских и интеграционных исследований Института мировых цивилизаций. Адрес: 119049, Москва, Ленинский проспект,1/2, корп. 1. E-mail: nkondratieva@inbox.ru

DOI: http://dx.doi.org/10.15211/soveurope620186272 
для активизации торгово-экономических отношений между РФ и ЕС и разработки концепции общего экономического пространства. Элементы рыночной модели ЕС рассматриваются как полезные образцы для развития интеграционных процессов на постсоветском пространстве.

Задачи настоящей статьи: представить устоявшиеся организационные принципы и механизмы функционирования ЕВР как две проекции, дополняющие статистическую проекцию этой модели. Предпочтение отдано поиску доступных наблюдению фактов о едином внутреннем рынке ЕС и его элементах, то есть поиску инструментов анализа ЕВР. При сопоставлении идейных основ и практики учтено, что нынешнее состояние ЕВР - это результат постоянных целенаправленных усилий Евросоюза во имя получения убедительных свидетельств успешности своей модели. Сформированное представление о ЕВР может послужить основанием для дальнейшей операционализации этого понятия и изучения индикаторов его развития.

\section{Традиционные индикаторы}

Для оценки результатов ЕВР используют такие показатели, как динамика ВВП, региональная торговля, ПИИ, мобильность населения. Отметим, что за время существования ЕВР, эти показатели не отличались стабильностью. Благоприятными для экономики и социальной сферы стали 1994-2000 гг. и 2004-2007 гг. В 2000 г. показатель роста ВВП подскочил до 3,5\%, в 2006 и 2007 г., соответственно, до 3,1 и 3,0\%; результативным стал и 2017 г. (2,4\%). В 1993, 2009 и 2012 гг. были зафиксированы отрицательные значения показателя. За четверть века торговля товарами внутри ЕС выросла в четыре раза (с 800 в 1994 г. до 3063 млрд евро в 2015 г.). Значительно увеличилась численность граждан, проживающих в другом государствечлене (с 4,6 млн в 1995 г. до 16 млн в 2015 г.). Хотя в целом работающих за пределами страны своего гражданства не так много - 11,3 млн человек, 3,7\% от общей численности рабочей силы в $\mathrm{EC}^{1}$.

Последнее десятилетие, однако, глобальные рынки стали фактором опережающего роста конкурирующих экономик, главным образом Китая. Доля Евросоюза в глобальной торговле товарами и услугами сократилась с 19\% в 2007 г. до 16,7\% в 2017 г., а доля Китая выросла с 9,3 до 13,4\%. Китаю удалось потеснить и США, хотя не столь заметно (доля США сократилась с 15,5 до 14,5\%) ${ }^{2}$. Те же тенденции наблюдаются на рынках капиталов: если до 2008 г. страны ЕС были основными получателями глобальных ПИИ, то с 2008 г. начинается сдвиг в распределении ПИИ в пользу догоняющих экономик, главным образом Китая. За 2017 г. ПИИ в ЕС уменьшились почти в десять раз (37 млрд против 340 млрд в 2016 г.) $)^{3}$ из-за массового изьятия средств американскими компаниями, а также ужесточения европейской процедуры проверки ПИИ на предмет их “чистоты”, что отпугнуло инвесторов из СНГ и Азии.

Что же объединение рынков даёт европейцам сегодня. Отделить влияние ЕВР от влияния других факторов, определивших динамику этих показателей, непросто,

125 years of the EU Single Market: Key achievements (2018) URL: http://www.europarl. europa.eu/resources/library/media/20180116RES91806/20180116RES91806.pdf

${ }^{2}$ DG Trade Statistical guide. (2018) P. 21 URL:

http://trade.ec.europa.eu/doclib/docs/2013/may/tradoc_151348.pdf

${ }^{3}$ Large fall in EU Foreign Direct Investment flows in 2017 13.07.2018 URL:

https://ec.europa.eu/eurostat/web/products-eurostat-news/-/DDN-20180713-1 ?inheritRedirect=true

Современная Европа, 2018, №6 
но такие расчёты периодически проводятся. Например, по официально принятой оценке добавочная доля торговли, которая опирается на правила ЕВР, дополняющие правила ВТО, равна $60 \%$. Понятно, что это примерная оценка. Некоторые показатели - практически прямой результат перераспределительных программам общего бюджета. Например, значительное увеличение количества студентов, обучающихся в других странах ЕС (с 3 тыс. в 1988 г. до 272 тыс. в 2014 г.) во многом получено благодаря программе Erasmus, запущенной в 1987 году.

Очевидно, что в оценке европейской рыночной модели нельзя руководствоваться только цифрами. Преимущества ЕВР всегда носили качественный характер и обязаны его особому организационному устройству, содействующему передвижениям.

\section{определение}

Единый внутренний рынок ЕС называют пространством без внутренних границ и пространством четырёх свобод. Анализ положений Договора о функционировании ЕС позволяет уточнить, что речь идёт о пространстве, характеризуемом совокупностью полномочий (компетенций) наднациональных институтов, а также правами экономических субъектов - акторов этого пространства - в вопросах передвижения. Под ЕВР следует понимать систему регулирования экономической деятельности на определённой территории, предполагающую свободу передвижения как принцип, способы достижения определенного единства регулирования, такие как общее законодательство и экономическая политика, направленные на упорядочение протекционистских барьеров, а также его ожидаемые результаты: сближение условий хозяйственной деятельности, облегчение обмена и возможность снижения дефицита факторов экономического развития.

Схема организации ЕВР

\begin{tabular}{|c|c|c|}
\hline Сферы организации & свобода передвижения & конкуренция \\
\hline Принципы регулирования & $\begin{array}{l}\text { запрет дискриминации, гар- } \\
\text { монизация, взаимное при- } \\
\text { знание }\end{array}$ & честная конкуренция \\
\hline Направления регулирования & $\begin{array}{l}\text { товары, услуги, капиталы, } \\
\text { лица }\end{array}$ & $\begin{array}{l}\text { концентрация, монополиза- } \\
\text { ция, господдержка }\end{array}$ \\
\hline Методы регулирования & $\begin{array}{l}\text { контроль, бюджетное пере- } \\
\text { распределение, общая поли- } \\
\text { тика, право }\end{array}$ & $\begin{array}{l}\text { контроль, общая политика, } \\
\text { право }\end{array}$ \\
\hline
\end{tabular}

\section{Идейная основа}

Более детальное представление о ЕВР может быть составлено из совокупности теоретических воззрений на экономическую интеграцию, а также практических результатов работы единого рынка, в том числе тех, что были достигнуты в ходе укрепления его конструкции. В соответствии с классической и неоклассической теорией свобода торговли ЕВР стимулирует экономических акторов к поиску сравнительных преимуществ, увеличивая предложение товаров и услуг в каждой его страСовременная Европа, 2018, №6 
не. Торговля товарами компенсирует недостаток дефицитных производственных факторов. Классическая теория полагает, что повышение эффективности происходит за счёт перемещения капитала или людей, дополняющих перемещение товаров. Это содействует межстрановому сближению цен на товары и производственные факторы, выравнивая благосостояние стран. При этом конкурентная борьба, являясь ценностью открытых рынков, служит движущей силой и условием получения выгоды. Именно она генерирует импульсы для поиска сравнительных преимуществ: повышения качества и удешевления отечественных товаров; совершенствования разделения труда; специализации. Таким образом, на классической теории построены две опоры единства рынков - свобода передвижения и конкуренция.

Неоклассика помогает учесть риски, вытекающие из свободного передвижения и конкуренции, а именно: выигрыш для владельцев одних производственных факторов и проигрыш для других. Соответственно рекомендует целенаправленные усилия по более равномерному и социально справедливому перераспределению благ.

В логике альтернативных теорий ЕВР стал средой для экономики масштаба. Высока его ценность как источника повышенного спроса, позволяющего акторам торговли выйти за кривую своих возможностей, дополнительно снижать цену единицы продукции, увеличивать объём продаж и занятость, количество рентабельных видов деятельности, повышать разнообразие предложения. Качественный рост, сокращение производственных издержек и оздоровление экономики - результат внутриотраслевой кооперации, создания межфирменных альянсов, производственных цепочек и обмена технологиями.

Вместе с тем не упущены из виду негативные стороны укрупнения бизнеса монополизация рынка с последующей деформацией условий конкуренции из-за злоупотреблений доминирующим положением отдельных фирм. Поэтому, оправданы меры в рамках национальной конкурентной политики по поддержке предприятий со слабыми финансовыми мускулами во избежание чрезмерной концентрации производства и капитала. Отметим также, что теоретиками и практиками оценены риски перехода отдельных предприятий на такие безответственные способы борьбы, как снижение качества товаров и производственных условий, а также ответные национальные меры поддержки компаний, такие как налоговые льготы, защита географических наименований и уникальной продукции, разработка национальных торговых и технических правил. Названные меры оправданны при условии, что они не служат одновременно скрытым орудием протекционизма.

Важно то, что ни идеи о преимуществах либерализации торговли, ни обратные аргументы о её рисках, описанные в классических и альтернативных торговых теориях, не упущены творцами ЕВР. Риски не стали поводом для отказа от либерализации, а истолкованы как неизбежные издержки новых возможностей развития. Созданы и продолжают совершенствоваться регуляционные механизмы, для того чтобы помочь каждому субъекту ЕВР воспользоваться преимуществами свободы передвижения.

\section{Принципы и политика функционирования}

Основу наднационального регулирования, а точнее координирования ${ }^{1}$, составляют: ${ }^{1}$ В попытке отмежеваться от государственного регулирования и присущих ему противоречий, а также
в свете критики российской модели, эксперты в ЕС стали называть модель ЕВР координируемой рыночной экономикой.

Современная Европа, 2018, №6 
- отправные принципы интеграции рынков, ведущие к ликвидации одних барьеров и упорядочению/унификации других,

- общая отраслевая политика, нацеленная на защиту прав потребителей, охрану труда, сохранение культурного многообразия и структурно сбалансированное развития экономики, пресечение нечестной конкуренции.

Принципы EBP и установки общей политики - воплощение либерального духа и главные ориентиры для его акторов. Анализ применения принципов ЕВР в решениях судебной инстанции по фактам ограничений свободы передвижения товаров, услуг, капиталов и лиц позволяет утверждать, что при толковании мер государственного протекционизма применяются экономические доводы [свод решений: Barnard, 2010]. Одни протекционистские меры истолкованы как злонамеренные и запрещены, чтобы поощрить новые торговые потоки и ликвидировать неоправданные издержки. Другие меры протекционизма оправданны, так как столь же важно поощрять свободу национальных торговых правил, конкуренцию торговых режимов как наиболее эффективный и экономный способ работы рыночного механизма. Руководствоваться одним каким-то принципом принято с оглядкой на другие. Соответственно, увидеть и понять общую адекватную картину ЕВР можно лишь складывая их, как пазлы, в определённом сочетании.

Принцип недискриминации направлен на борьбу с ограничениями торговли. Практика его применения позволила выработать два основных правила. Первое: запрещены выборочные хитроумные ограничения на передвижение товаров, услуг, капиталов и людей. Если государство накладывает запрет на ввоз в страну товара из каких-то разумных соображений (защиты морали, государственной безопасности, здоровья и жизни людей и животных, сохранения растений, национальных сокровищ или коммерческой собственности), то запрет должен в равной мере относиться к отечественной продукции, то есть его нельзя применять выборочно. Второе: запретительная мера возможна, если её применять, не выходя за пределы необходимого для достижения целей запрета. Запрет не должен напоминать дискриминационную схему, отпугивающую иностранных производителей и вынуждающую их повышать издержки, а потребителя - отдавать предпочтение отечественному товару, в результате ведущую к отказу от создания новых торговых потоков. Таким образом, протекционистские меры соотнесены с ценностными ориентирами EC в экономической политике так, чтобы минимизировать ущерб его кредо - либерализму, но одновременно поддержать высокие жизненные стандарты и образ сильного игрока на мировой арене.

Взаимное признание правил, норм, стандартов государств-членов - второй столь же простой и оригинальный принцип преодоления барьеров на пути передвижения факторов и результатов экономической деятельности и сохранения свободы национальных торговых правил и норм. Назначение этого принципа - сокращать издержки, связанные с приобщением к требованиям целевого рынка; расширять палитру товаров и услуг, развивать экономику разнообразия. Взаимное признание дает потребителю возможность выбирать между относительно низкой стоимостью товаров/услуг или их повышенными качественными характеристиками.

Взаимное признание работает в сочетании с гармонизацией - третьим принципом. Гармонизация норм в пределах ЕС обусловлена необходимостью минимизировать неотзывчивость предпринимателей на запросы потребителей и требования

Современная Европа, 2018, №6 
охраны труда, а также направлять политику государств-членов, особенно тех, что беднее, и потому сдерживают повышение социальных стандартов с целью привлечь инвестиции. В таких сферах, как право потребителя, здоровье, окружающая среда, труд, территориальное развитие, принудительная гармонизация стандартов и норм позволяет защитить социальные интересы и дополняет принципы свободы передвижения и взаимного признания.

Важно отметить, что гармонизация не тормозит высокотехнологичную экономику, но в то же время помогает избегать монополизации рынка передовым разработчиком. Национальные органы могут принимать жёсткие национальные торговые требования и технические стандарты, превышающие гармонизированные общеевропейские нормы. Но в таких случаях, повышенные нормы обязательны к применению только на этом национальном рынке и могут быть использованы как дополнительное конкурентное преимущество, а гармонизированные нормы применяются на недискриминационной основе как элемент солидарности с догоняющими государствами-членами. В итоге задача гармонизации состоит в том, чтобы принести выигрыш всему рынку, создав предсказуемую безопасную для потребителей среду и совместив производственные процессы.

Необходимо отметить ещё и то, что на пространстве ЕВР национальные и наднациональные интересы перманентно конкурируют. Протекционистские меры запрещены ровно до тех пор, пока не будет доказан общественный интерес, преобладающий над свободой передвижения. В этом случае могут быть учреждены новые торговые правила и защитные меры. Однако рано или поздно кто-либо может потребовать доказательства правомерности введенных торговых правил. Такая ситуация неопределенности опять же подобна конкуренции, в которой результат зависит от силы приведенных аргументов. И она, как свидетельствует опыт, предпочтительнее заранее предопределенным условиям.

Соблюдение принципов ЕВР приводит национальные рынки с их стандартами и правилами в состояние самокоррекции. Их применение не влечёт за собой ухудшение чьего-либо благосостояния. Созданию единой правовой среды и контролю над исполнением правовых норм служат наднациональная конкурентная и экологическая политики, практически незатратные для ЕС и обременяющие (нормами) всех акторов ЕВР в равной мере. Наконец, поскольку интеграция не гарантирует быстрого выравнивания условий хозяйствования, на помощь приходит социально ориентированное регулирование, предусматривающее расходы на региональное, сельскохозяйственное, транспортное, научно-техническое развитие из бюджета ЕС. Осуществляемое не через перераспределение от богатых к бедным, ставящего одни страны в зависимость от других, а на основе доступа всех акторов к финансированию и конкуренции заявок. На основании изложенного можно сделать вывод о том, что регулирование ЕВР стремится к оптимальности по Парето. Изучение взаимодействия институтов ЕС с теми или иными субъектами регулирования (производителями, социальными группами, странами и регионами) привело профессора Лондонской школы экономики и политических наук С. Хикса к аналогичной точке зрения [Hix, 2005].

Особо стоит отметить, что общие отраслевые политики, как и принципы, на которых строится ЕВР, определяющие допуск на рынки товаров, - это оптимальный (по Парето), самый дешевый для преуспевающих стран вариант проявления солидарности с бедными. Этот довод также подтверждает экономичность модели ЕВР. 


\section{Вспомогательные институты и механизмы}

ЕС ежегодно тратит на содержание своего управленческого аппарата 10 млрд евро, и главные расходы идут на деятельность, связанную с регулированием ЕВР.

Как представляется, единый рынок получил признание благодаря силе его правилам и институтам, регулирующим экономику и модернизацию общественных отношений. И действительно, он впечатляет, если учесть, как много протекционистских барьеров устранено. Без наднационального регулирования Европа сегодня могла бы быть фрагментированным пространством, состоящим в основном из слабых игроков.

Чтобы обеспечить эффективную работу ЕВР, учреждены правовые, контрольные, перераспределительные и прочие вспомогательные механизмы. Практически ежедневно право ЕВР прирастает новыми законодательными актами и прецедентными судебными решениями. На конец 2017 г. насчитывается 1038 директив и 4100 регламентов, регулирующих $\mathrm{EBP}^{1}$. Европейская комиссия и суд ЕС наделены полномочиями, чтобы противодействовать практике, которая могла бы ослабить эффект интеграции для одних акторов ЕВР и усилить его для других. Сеть СОЛВИТ (SOLVIT), диспетчерская служба для граждан, интерактивный информационный портал "Ваша Европа"2 выполняют вспомогательные функции. Они были учреждены в начале 2000-х гг., чтобы разгрузить судебные органы, решать споры в досудебном порядке, принуждать к соблюдению установленных европейских норм.

В 2018 г. отметила своё десятилетие служба административного сотрудничества ИМИ (The Internal Market Information System). Последние годы, когда во всем мире цифровизация стала сферой особой заботы и применения передовых идей, увеличилась востребованность электронного обмена документами. На базе ИМИ учреждена Европейская профессиональная карта - электронное свидетельство признания квалификации, выдаваемое с помощью онлайн-процедуры. Карта действует уже три года и значительно облегчила устройство на работу в других странах ЕС.

Для информирования общественности о результатах перенесения в национальное законодательство принятых на уровне ЕС директив, ведения статистики нарушений со стороны государств-членов, предупреждения нарушений и выправления ситуации с 2013 г. действует онлайн-портал Индикаторное табло ЕВР. Отметим, что дефицит транспозиции директив - устойчивая проблема ЕВР. Основная причина проста - государства не успевают их внедрять. Новых директив достаточно много. Например, в 2016 г. государства обязаны были внедрить в национальное право 66 новых директив (более двух в месяц), в 2015-м - 47, в 2017-м - 39; долги по ранее вышедшим директивам тормозят имплементацию новых директив. Между тем по трем десяткам директив задержка имплементации составляет 2-10 лет (по оценке ЕК на декабрь 2018 г.) [Single Market Scoreboard, 2018], что говорит о сопротивлении ряду норм. В целом же о сопротивлении самой модели говорить не приходится. Судя по всему, она более устраивает европейцев, нежели, к примеру, классическая либеральная модель США с полной конкуренцией стандартов.

\footnotetext{
${ }^{1}$ Single Market Scoreboard 07/2018 URL: http://ec.europa.eu/internal_market/ scoreboard/performance_by_governance_tool/transposition/index_en.htm\#maincontentSec4

${ }^{2}$ СОЛВИТ http://ec.europa.eu/solvit Диспетчерская служба для граждан http://ec.europa.eu/citizensrights/, "Ваша Европа" http://ec.europa.eu/youreurope
}

Современная Европа, 2018, №6 
Чтобы контролировать безопасность товаров, действуют тысячи аккредитованных Евросоюзом сертификационных лабораторий. Специализированная онлайнсистема оповещения рынка пищевых продуктов и кормов RASFF и аналог для рынка непищевой продукции RAPEX распространяют информацию об угрозах, поступающих из государственных инспекций, когда недоброкачественные товары всетаки попадают на ЕBP.

Как видно, модель сложна в организации. Взамен государства-члены и компании имеют возможность влиять на интеграцию рынков, участвовать в обсуждениях будущих законов. Для этого созданы отраслевые комитеты и форумы. Действует обязательный порядок открытого обсуждения официальных сообщений Еврокомиссии о намерении изменить правовую ситуацию в том или ином сегменте ЕВР. В таких обсуждениях участвуют все заинтересованные акторы, в том числе из государств, не входящих в Евросоюз. Пожалуй, наиболее ярким примером стало практически общемировое обсуждение проекта Регламента №1907/2006 об учреждении Европейского химического агентства и механизма регистрации, оценки, авторизации и ограничения химических веществ на пространстве единого рынка $(\mathrm{REACH})$. Наконец, нельзя не упомянуть о возможности лоббирования интересов в технических организациях по стандартизации EC (CEN, CENELEC и ETSI). Как юридические, так и физические лица отстаивают свои интересы в досудебном порядке.

ЕВР удобен для потребителей и экономических акторов. С одной стороны, эта система сводит к минимуму случаи, в которых потребитель выходит один на один с поставщиками некачественных товаров или услуг и поставлен перед необходимостью защищать свои права в судебном порядке. С другой стороны, система обеспечивает защиту поставщиков. Основанная на декларировании ответственности производителя/поставщика за качество, оценке товаров и услуг независимыми органами, ответственности государств за изъятие по причине несоответствия нормам, информировании, правилах перемещений, в том числе регистрации опасных товаров, диалоге между законодателями и субъектами права, а не на запретах и штрафах (они применяются, когда другие меры воздействия исчерпаны) эта система не наносит прямого вреда отдельным отраслям и производствам, поощряет конкуренцию стандартов и норм, соревнование наднационального и национального начал.

\section{Пределы применения модели}

Несмотря на привлекательность, в описанной модели есть и слабые стороны. Главная, на наш взгляд, - её несостоятельность за пределами ЕС. Отметим, что ЕС позиционирует свою модель как цивилизационный ориентир, полагая, что прочный теоретический базис, длительный период апробации, общественное согласие и согласие государств-членов, ориентация на устойчивое развитие дают ему право на распространение модели. Для продвижения своих подходов к регулированию торгово-экономических отношений и организации рыночного пространства Европейский Союз использует так называемые партнёрства и отраслевые диалоги с внешними странами и регионами. Проблема в том, что они не дают ожидаемых результатов, наиболее ярким примером чему может служить замороженное Трансатлантическое торгово-инвестиционное партнерство ЕС - США. Многие догоняющие, да и развитые экономики не готовы на соглашения с Евросоюзом. В вопросе своей конкурентоспособности одни опираются на господдержку или социальный дем-

Современная Европа, 2018, №6 
пинг, другие полагаются на самокоррекцию рынка или на самостоятельность его акторов. Тем не менее в последнее время ЕК удалось открыть несколько новых площадок для переговоров: в 2017 г. подписан меморандум с Комиссией по национальному развитию и реформам Китая о начале диалога по контролю государственной помощи; соответствующие переговоры открыты с Чили и Азербайджаном и продолжены с Мексикой, Меркосур и Индонезией.

Ряд противоречий проистекает из привлекательности пространства ЕВР для мировых компаний: сами европейцы оказываются в стесненных условиях, способы же поддержки европейских компаний вызывают у внешних акторов недоверие. В США, к примеру, говорят так: американцы защищают конкуренцию, в то время как европейцы защищают конкурентов.

В последние годы Евросоюз наращивает противодействие доминированию американских компаний на пространстве ЕВР. В частности, отслеживает случаи предоставления неоправданных налоговых преимуществ для транснациональных корпораций. В 2017 г. на Люксембург было наложено обязательство получить 250 млн евро в виде неоплаченного налога с Amazon, плюс процент. ЕК также изучила дистрибьюторские соглашения Amazon с издателями электронных книг в Европе и набрала достаточно фактов для открытия расследования о нарушении антимонопольного законодательства ЕС. На 2,5 млрд евро оштрафован Google за манипуляции с использованием его флагманского продукта - поисковой системы и сервиса сравнения покупок ${ }^{1}$

Официальный ЕС приветствует проекты кооперации, когда риск для подрыва конкуренции сведен к минимуму. Наиболее заметным событием 2017 г. стало решение Комиссии одобрить слияние между Bayer и Monsanto. Слияние было разрешено при условии, что компании продадут конкурентам активы на сумму более шести миллиардов евро, а также продолжат вкладывать деньги в НИОКР по внедрению менее токсичных пестицидов. Таким образом, было соблюдено требование ЕК о сохранении конкуренции и инноваций на рынке семян и пестицидов.

В целом, несмотря на всю сложность адаптации внешних партнеров к европейской модели, за 25 лет они по крайней мере вынуждены ей следовать на самом пространстве ЕВР, что косвенно приводит к эволюции глобальной культуры конкуренции и организации рынка.

\section{Выводы и рекомендации}

Единый внутренний рынок ЕС - это межгосударственное пространство, в котором упразднена барьерная функция внутренних государственных границ, упорядочены национальные препятствия рыночным отношениям, запрещены дискриминационные ограничения на передвижение товаров, услуг, капиталов, рабочей силы, юридических и физических лиц, снижаются пространственные различия факторов и результатов экономической деятельности. Это определение даёт возможность дальнейшего операционального изучения ЕВР на основе количественных и качественных индикаторов, позволяющих судить об объеме, содержании, результатах работы его механизмов, комплексно оценивать интерес экономических акторов к законодательному процессу, количество обращений в суды и вспомогательные учреждения, сближение условий и результатов хозяйственной деятельности с целью подтверждения гипотезы об успешности модели.

\footnotetext{
${ }^{1}$ Report on Competition Policy 2017. Brussels, 18.6.2018.

http://ec.europa.eu/competition/publications/annual_report/2017/partl_en.pdf

Современная Европа, 2018, №6
} 
Порядок передвижения товаров, услуг и лиц по пространству ЕВР носит свободный характер, но не безусловный. Действуют национальные и наднациональные требования и практики. В совокупности они провоцируют конкуренцию между станами и создают возможности для закрепления передового опыта.

Несомненный положительный итог объединения рынков государств Евросоюза - высокое качество жизни и деловой среды. Вместе с тем изучение торговых и интеграционных теорий, а также практики ЕВР позволяет заключить, что выгоды и издержки либерализации экономических отношений неоднозначны. Неопределённость провоцирует скрытые формы национального протекционизма и неконкурентного поведения компаний, таким образом, возведена теорией в разряд главных проблем интеграционного пространства. В пределах ЕВР эта проблема решается корректирующей деятельностью наднациональных институтов, направленной на повышение предсказуемости интеграционного пространства для его акторов, достижимость в обозримом будущем прогнозируемых положительных эффектов, таких как ускорение процессов экономического роста, модернизации экономики, разумного снижения издержек экономической деятельности, сбалансированного социально-экономического развития территории.

Членство России в ЕАЭС диктует необходимость оценки этого союза с учётом достижений европейской модели. Последнее время институты ЕАЭС стали объектом конструктивной критики. Отмечены, с одной стороны, неспособность ЕАЭС предотвратить внутренние торговые конфликты и минимизировать хитроумную деятельность стран-участниц по защите государственных интересов и рынков, с другой - прогресс в создании регулирующих норм и интенсивный поиск, который ведет Евразийская экономическая комиссия по налаживанию официальных отношений с Евросоюзом. Такие отношения возможны только при условии приверженности ЕАЭС защите прав потребителей, свободы предпринимательства, честной конкуренции и независимости институтов.

Отсюда, целесообразно:

- сместить акценты от снижения количества иностранных товаров на внутреннем рынке ЕАЭС к защите от товаров ненадлежащего качества. Для этого общее законодательство и контроль его исполнения необходимо развивать параллельно, как два регуляционных процесса с целью обеспечить повышение качества товаров и услуг;

- преодолеть предубеждение относительно использования энергетики и транзитной инфраструктуры в качестве инструментов политического влияния отдельных членов или ЕАЭС в целом и снять возникающие в связи с этим угрозы для стран-потребителей; точно также самим государствам-членам необходимо избавиться от преследующего их фантома советской империи, в том числе боязни потери суверенитета в экономике.

Это возможно при условии: а) соревнования наднационального и национального начал, б) многоуровневого регулирования энергетики и транспорта, обеспечивающего их нейтралитет и надлежащее развитие, в) постепенного повышения веса исполнительного и судебного институтов ЕАЭС как игроков, имеющих видение евразийской интеграции, и как институтов, обращение к которым доступно и эффективно.

Список литературы

Борко Ю., Любимова В., Федоров Л. (1963) Рабочее движение в странах “Общего рынка”. Мировая экономика и международные отночения. В 3. С. 81-90. 
Борко Ю.А. (2003) Социальные предпосылки европейской интеграции. В кн. От Европейской идеи - к единой Европе. М.: Деловая литература. С. 84-113.

Гутник В., Хесин Е. (2006) Европейские исследования: сохранение традиций и новаторские подходы. Мировая экономика и международные отношения. № 4. С. 84-92.

Иванов. И.Д. (2004) Единый внутренний рынок ЕС: свет, тени, историческая перспектива. Современная Европа. №2. Стр. 19-34.

Кондратьева Н.Б. (2017) Европейский союз: становление единого рынка. Доклады Института Европь, № 346, М.: Нестор-история. 143 с.

Механизм единого рынка / 1992 год: новые контуры Западной Европы. М.: Мысль. 1992.

Шишков Ю.В. (1979) Формирование интеграционного комплекса в Западной Европе: тенденции и противоречия. М.: Наука. 343 с.

\section{References}

1992 god: novye kontury Zapadnoi Evropy. Glava IV. Mekhanizm edinogo rynka (1992) M.: Mysl'. S. 50-70. Barnard C. (2010) The Substantive Law of the EU: The Four Freedoms (3rd ed.). Oxford, New York: Oxford University Press.

Borko Y., Lyubimova V., Fedorov L. (1963) Rabochee dvizhenie v stranah "Obshchego rynka". Mirovaya ehkonomika i mezhdunarodnye otnosheniya. V 3. S. 81-90.

Borko Y.A. (2003) Social'nye predposylki evropejskoj integracii. - Ot Evropejskoj idei k edinoj Evrope.

M.: Delovaya literatura. S. 84-113.

Ivanov. I.D. (2004) Edinyj vnutrennij rynok ES: svet, teni, istoricheskaya perspektiva. Sovremennaya Evropa. № 2. S. 19-34.

Gutnik V., Hesin E. (2006) Evropejskie issledovaniya: sohranenie tradicij i novatorskie podhody. Mirovaya ehkonomika i mezhdunarodnye otnosheniya. № 4. S. 84-92.

Hix S. (2005) The political system of the European Union. Second edition. Palgrave Macmillan. P. 235-239.

Jean-Claude Juncker. Candidate for President of the European Commission. A New Start for Europe: My Agenda for Jobs, Growth, Fairness and Democratic Change. Political Guidelines for the next European Commission. Opening Statement in the European Parliament Plenary Session Strasbourg, 15 July, 2014 URL: https://ec.europa.eu/commission/sites/beta-political/files/juncker-political-guidelines-speech_en.pdf

Kondrat'eva N.B. (2017) Evropejskij soyuz: stanovlenie edinogo rynka. Doklady Instituta Evropy, № 346, M.: Nestor-istoriya. 143 s.

Report on single market integration and competitiveness in the EU and its member states (2015) European Union. $115 \mathrm{p}$.

Single Market Scoreboard: Compliance with EU law improves, but needs work.13.07.2018. URL: https://ec.europa.eu/growth/content/single-market-scoreboard-compliance-eu-law-improves-needs-work_en

Shishkov Y.V. (1979) Formirovanie integracionnogo kompleksa v Zapadnoj Evrope: tendencii i protivorechiya. M.: Nauka. $343 \mathrm{~s}$.

Study on the Impact of the Single Market on Cohesion: Implications for Cohesion Policy, Growth and Competitiveness, 2011 URL:

http://ec.europa.eu/regional_policy/sources/docgener/studies/pdf/single_market/single_market_report.pdf

\section{EU market integration model: quarter-century of improvement}

Author: Kondratyeva N., Candidate of Economic Science, Associate prof., Scientific Secretary of the Institute of Europe RAS. Address: 11-3, Mokhovaya str., Moscow, Russia, 125009. Associate prof. of Higher School of Economics. Address: 20, Myasnitskaya str., Moscow, Russia, 101000. Head of Department of European and integration studies of the Institute of world civilizations. Address: 1/2, Leninsky Prospekt, korp. 1, Moscow, Russia, 119049. E-mail: nkondratieva@inbox.ru

Abstract. The article presents a vision of the EU internal market's structure, its logic and methods of regulation, conceived in 1950-1980s and tested by 25 years of practice. Based on the operationalist approach, the search for the content of the concept of a single market has been carried out. The purpose of the article is to present the EU internal market as a functioning model with a fundamental basis and interrelated mechanisms. The proposed definitions and vision of the European model of market integration can serve as a methodological basis for further description of the phenomenon, analysis of indicators of its development and conceptual issues of Eurasian economic integration.

Key words: EU, single internal market, integration theories, European economic model.

DOI: http://dx.doi.org/10.15211/soveurope620186272 